\title{
Escollos y legados en la aplicación del armisticio de Trujillo en las provincias del sur de Colombia, 1820-1821 ${ }^{1}$
}

\section{Difficulties and legacies in the application of the Trujillo armistico in the provinces of southern Colombia, 1820-1821}

DOI:https://doi.org/10.25100/hye.v16i54.9907

Artículo recibido: 9-06-2017 Artículo aceptado: 01-02-2020

\section{Roger Pita Pico}

Politólogo con opción en Historia de La Universidad de los Andes (Bogotá), Especialista en Gobierno Municipal, Especialista en Política Social y Magíster en Estudios Políticos de la Pontificia Universidad Javeriana. Miembro de Número de la Academia Colombiana de Historia, Miembro Correspondiente del Instituto de Geografía e Historia del Brasil y Miembro Correspondiente de la Real Academia de la Historia de España.

Academia Colombiana de Historia, Bogotá.

Correo electrónico: rogpitc@ hotmail.com

ORCID: 0000-0001-9937-0228

Forma de citar este artículo: Pita Pico, Roger. "Escollos y legados en la aplicación del armisticio de Trujillo en las provincias del sur de Colombia, 1820-1821". Historia y Espacio, vol. 16 n $^{\circ} 54$ (2020): 73-102. Doi.org/10.25100/hye.v16i54.9907.

1 Artículo Tipo 2: de reflexión, según clasificación de Colciencias. Resultado de una investigación más amplia titulada: "Las rutas de la paz y la negociación durante el proceso de Independencia de Colombia, 1810-1825”. Este trabajo fue financiado con recursos propios del autor. 


\section{Resumen}

En el marco del Bicentenario de la Independencia de Colombia, este artículo tiene como mira analizar el armisticio de Trujillo firmado en 1820 y observar su implementación en las provincias del sur de Colombia. En medio de un ambiente generalizado de desconfianza e incertidumbre, surgieron inconsistencias en la toma de decisiones y vacíos normativos que generaron dilaciones, no solo en la notificación del acuerdo en cada una de las áreas en disputa, sino también en el proceso de fijación de límites. No obstante, aún con todos los tropiezos registrados, es indudable que el armisticio significó al menos un corto respiro en la frenética y cruda lucha militar; sentó las bases para la regularización de la guerra y les permitió a los republicanos contar con un tiempo valioso mientras el general Simón Bolívar lanzaba la campaña de liberación definitiva de estos territorios.

Palabras clave: conflicto armado, paz, armisticio, Independencia, Pasto, Popayán, siglo XIX.

\section{Abstract}

Within the framework of the Bicentennial of the Independence of Colombia, this article aims to analyze the Trujillo armistice signed in 1820 and specifically to observe its implementation in the southern provinces of Colombia. In the midst of a generalized environment of mistrust and uncertainty, there were inconsistencies in decision making and regulatory gaps that generated delays not only in notification of the agreement in each of the disputed areas but also in the setting of limits. However, despite all the setbacks, there is no doubt that the armistice meant at least a short respite from the frantic and difficult military struggle, laid the foundations for the regularization of the war, and allowed the Republicans to count on valuable time while General Simon Bolivar launched his campaign for the definitive liberation of these territories.

Keywords: armed conflicto, peace, armistice, Independence, Pasto, Popayán, nineteenth century. 


\section{Roger Pita Pico}

\section{Escollos y legados en la aplicación del armisticio de Trujillo en las provincias del sur de Colombia, 1820-1821}

\section{Introducción}

El panorama social, económico ${ }^{2}$, político y militar vivido en el sur de Colombia durante el proceso de Independencia fue bastante conflictivo. Allí las luchas habían sido más cruentas y prolongadas. Era indudable el apoyo que habían logrado enraizar en este territorio los sentimientos monárquicos.

Cuantiosos esfuerzos y gastos requirieron los patriotas para expulsar a los realistas durante el período de la primera República Federativa. Mientras en otras provincias liberadas se trenzaban en un agudo debate interno y en un conflicto militar sobre la forma de gobernarse, aquí, en esta región del sur, los realistas, con el apoyo de la Audiencia de Quito, todavía no se resignaban a abandonar definitivamente el territorio. La fuerza avasalladora de la Reconquista española llegó a estas provincias con la victoria obtenida el 29 de junio de 1816 en la batalla de la Cuchilla del Tambo ${ }^{3}$ y garantizó por tres años más el restablecimiento absoluto del régimen monárquico.

Después del triunfo obtenido el 7 de agosto de 1819 en la batalla de Boyacá, los patriotas siguieron encontrando en el sur serios tropiezos para sus planes de extender hasta estos territorios los principios del sistema liberal e independiente. El paso del Juanambú y las guerrillas del Patía se convirtieron en el símbolo de la resistencia realista y en el tormento para el ejército republicano ${ }^{4}$.

2 Desde los tiempos del dominio hispánico, la economía en estas tierras del sur era impulsada por la producción de sus grandes haciendas dedicadas al cultivo de la caña de azúcar, la elaboración de mieles y la cría de ganado en el valle circundante a la ciudad de Cali, la producción agropecuaria en la zona de vertiente de Popayán y Pasto y la explotación del oro en las zonas de la costa pacífica con mano de obra esclava. Zamira Díaz de Zuluaga, "La fuerza de trabajo en el Cauca grande: 1810-1830”, en Independencia: ensayos de historia social, ed. Germán Colmenares (Bogotá: Instituto Colombiano de Cultura, 1986), 32.

3 Simón B. O'Leary, Memorias del general O'Leary (Caracas: Imprenta de la Gaceta Oficial, 1983), tomo 17: 368 .

4 Roberto Cortázar (comp.), Cartas y mensajes del general Francisco de Paula Santander (Bogotá: Academia Colombiana de Historia, 1956),2: 62. Sobre la dificultad de las operaciones 
Las continuas derrotas militares, el decidido apoyo de los sectores populares, la fuerte influencia política de la Iglesia a favor del sistema monárquico y la presencia de fuerzas irregulares que colaboraron activamente con las tropas del rey fueron factores que ayudan a explicar la poca efectividad y el escaso alcance del movimiento emancipador en esa región ${ }^{5}$.

La zona del Valle del Cauca fue la primera en ser recuperada. Popayán fue el epicentro de la confrontación militar con victorias intermitentes para uno y otro bando, mientras que Pasto se erigió como el bastión de la monarquía ${ }^{6}$. A principios de 1820, el contexto externo mostraba también signos de agitación. En España, la crisis se acentuó ante la disputa entre absolutistas y liberales. Tras el pronunciamiento de Riego, fueron convocadas las cortes y se restableció la Constitución de Cádiz a la cual el rey Fernando VII debió elevar su juramento. Este retorno del liberalismo frustró el envío de refuerzos militares a América y causó divisiones y polarización al interior de las autoridades políticas y militares ${ }^{7}$. Las cortes expresaron su interés de restaurar el dominio español en América por medio de una amnistía general, para lo cual se mostraron dispuestas a hacer concesiones y a prometer a las fuerzas "insurgentes" que conservarían el poder sobre las provincias que hubiesen conquistado, pero con la condición de que debían depender de España ${ }^{8}$.

En consonancia con esta postura conciliadora, el comandante en jefe del ejército expedicionario español, don Pablo Morillo, propuso un armisticio al Congreso de Angostura9. Tras varias deliberaciones, este órgano legislativo decidió, el 11 de julio, buscar conjuntamente la paz, pero sobre la base del

militares en el paso de Juanambú, véase el relato de José Hilario López, Memorias (Bogotá: Editorial ABC, 1942), tomo 1: 46-50.

5 Eduardo Pérez O., La guerra irregular en la Independencia de la Nueva Granada y Venezuela 1810-1830 (Tunja: Universidad Pedagógica y Tecnológica de Colombia, 1982), 263-268.

6 Sergio Elías Ortiz, Colección de documentos para la historia de Colombia. (Época de la Independencia) (Bogotá: Academia Colombiana de Historia, 1964), tomo 1: 115-214.

7 Rebecca A. Earle, España y la Independencia de Colombia, 1810-1825 (Bogotá: Universidad de Los Andes, 2014), 187.

8 Academia Colombiana de Historia, Fondo Archivo del general Miguel de la Torre, tomo 1: 112116.

9 Antonio Rodríguez Villa, El teniente general don Pablo Morillo. Primer conde de Cartagena, marqués de la Fuerte (1778-1837) (Madrid: Tipografía de Fortanet, 1910), tomo 4: 206-232; Invitación hecha por el general Morillo al Congreso de los disidentes establecido en Guayana y a los jefes militares de los mismos para la terminación de aquella guerra y suspensión de hostilidades (Cádiz: Imprenta de Niel, hijo, Plaza de S. Francisco, 1820), 1-7. 
reconocimiento de Colombia como una república soberana e independiente ${ }^{10}$. Esta última exigencia desconcertó a los españoles y aplazó por un tiempo el acuerdo.

El 30 de agosto, el presidente Simón Bolívar anunció a sus oficiales que negociaría la paz cuando estuviesen ocupadas las ciudades de Pasto y Quito, para lo cual había enviado a esas tierras del sur al general venezolano Manuel Valdés. El Libertador estaba convencido de que los españoles no podían reconocer más territorio del que tuviesen ocupado al momento de firmar la paz $^{11}$.

Bolívar aceptó el 21 de septiembre dialogar en aras de la paz, y los factores que lo motivaron a optar por tal decisión fueron: los vientos favorables que podía traer la tendencia liberal que sacudía a España, los recientes y sucesivos triunfos obtenidos en el campo de batalla, la convicción de que el tiempo de tregua sería aprovechado para ganar más aliados a la causa independentista y porque se contaría con mayores oportunidades para disciplinar y organizar los milicianos bisoños que eran la base del ejército ${ }^{12}$. No obstante, era consciente también de los costos que acarreaba dicha medida en momentos en que los republicanos registraban mejores resultados militares, ante lo cual se temía que una suspensión de armas podía afectar las ventajas alcanzadas con tanto sacrificio $^{13}$.

Hacia finales de octubre, por los lados del sur, las huestes republicanas no habían logrado en la región avances sustanciales más allá del paso del Juanambú y, en virtud de este panorama, Bolívar expuso a Morillo las bases que debían inspirar el acuerdo de armisticio. En particular, el séptimo punto de esa propuesta inicial estipulaba que: La división del Sur conservaráel territorio que haya dejado a su espalda en su marcha a Quito y conservarálas posiciones en que se encuentre al acto de la ratificación del tratado ${ }^{14}$.

${ }^{10}$ Actas del Congreso de Angostura 1819-1820 (Bogotá: Biblioteca de la Presidencia de la República, 1988), 353 .

${ }^{11}$ Simón B. O’Leary, Memorias del General O'Leary, tomo 29: 173.

12 José Manuel Restrepo, Historia de la Revolución de la República de Colombia (Bogotá: Editorial Besanzon, 1858), tomo 3: 79.

${ }^{13}$ José Manuel Restrepo, Documentos importantes para la historia de la Revolución de la República de Colombia en la América Meridional (Medellín: Universidad de Antioquia - Universidad Nacional, 2009), CD, 699.

${ }^{14}$ Simón B. O’Leary, Memorias del General O’Leary, tomo 17: 515-516. 
Para noviembre, lograron disiparse varias diferencias y ambos gobiernos decidieron nombrar sus comisionados. Luego de tres días de deliberaciones, el acuerdo fue firmado el 25 de noviembre en la ciudad de Trujillo y refrendado a los dos días con un histórico encuentro amistoso entre Bolívar y Morillo en la población de Santa Ana ${ }^{15}$. En el encabezado del documento, ambos gobiernos expresaron su voluntad de superar las discordias, para lo cual había que dar un paso crucial que era la suspensión de todas las operaciones terrestres y marítimas durante el lapso de seis meses contados desde el momento en que se comunicara la ratificación de este convenio. No obstante, bajo el principio de la buena fe y de los deseos "sinceros" de terminar la guerra, el cese al fuego podía prorrogarse por el tiempo que fuese necesario mientras se desarrollaban las negociaciones.

Los integrantes de uno y otro ejército debían permanecer en las posiciones que ocupaban al momento de notificarles la suspensión de hostilidades, para lo cual era imperioso señalar límites "claros y bien conocidos". Para el caso del conflicto vivido en Venezuela se acordaron previamente los límites. Para las demás provincias en disputa, las del sur y las de la costa caribe colombiana, había que nombrar comisionados especiales para que llegaran a un arreglo "amigable". Si se llegaba a romper el armisticio, no podían reabrirse las hostilidades sin el previo aviso al adversario cuarenta días antes de que se ejecutara el primer acto de hostilidad.

Con el fin de brindar un testimonio de los principios "filantrópicos" que inspiraron a ambos gobiernos para terminar los excesos y horrores que habían caracterizado esta guerra ${ }^{16}$, se firmó el 26 de noviembre un tratado de regularización conforme al derecho de gentes y a las prácticas más humanas de las naciones civilizadas, cuyo punto central fue el canje de prisioneros ${ }^{17}$.

Al momento de firmarse el armisticio, los republicanos dominaban a Popayán mientras que las tropas españolas al mando de Basilio García permanecían atrincheradas en Juanambú protegiendo el acceso a la ciudad de Pasto, para lo cual contaban con los refuerzos enviados por el presidente

15 Jorge Mercado, Campaña de invasión del teniente general don Pablo Morillo 1815-1816 (Bogotá: Editorial Iris, 1963), 430-433.

${ }^{16}$ Entre las fases más violentas de las guerras de Independencia, no hay que olvidar la guerra a muerte declarada a mediados de 1813 en Venezuela por Bolívar en reacción a las continuas violaciones al derecho de gentes por parte de los españoles.

17 "Armisticio" (Trujillo, 1820), Archivo General de la Nación (AGN), Sección Colecciones, Fondo Enrique Ortega Ricaurte, Legaciones y Consulados, caja 121, carpeta 1, ff. 1r-8r. 
de Quito, don Melchor de Aymerich ${ }^{18}$. Antes de que llegaran noticias a estas tierras del sur sobre la firma de la tregua, el teniente coronel Ángel María Varela ocupó Barbacoas, ciudad que los españoles habían tratado de fortificar. El comandante Francisco García había liberado Esmeraldas y así quedó libre del dominio español la zona de la costa pacífica entre Cupica y Guayaquil ${ }^{19}$.

Pese a la manifiesta voluntad de paz, ambos bandos no dejaron de pensar en sus planes militares, y de contemplar todos los escenarios posibles, ya fuera con el éxito o el eventual fracaso del proyectado acuerdo de paz. Así, la idea de Bolívar era aprovechar el armisticio para venir él, al término de este acuerdo, a dirigir la campaña de liberación de Pasto y Quito, proyecto que el vicepresidente Francisco de Paula Santander, encargado de dirigir la guerra en esta parte del sur, valoró como "excelente y ventajoso" en vista de los sucesivos reveses militares allí padecidos ${ }^{20}$.

Teniendo en consideración estos antecedentes y, en el marco de la conmemoración del Bicentenario de la Independencia de Colombia, este artículo tiene como mira analizar el proceso de delimitación de territorios y cese al fuego decretado por el armisticio firmado en 1820 en Trujillo y, además, observar las complicaciones que giraron en torno a su aplicación en el sur de Colombia, en las provincias de Popayán y Pasto. El propósito es tener una visión integral sobre la aplicación de este tratado y sus consecuencias en el desarrollo de la fase final del conflicto vivido en este convulsionado marco territorial en vista de que la información disponible y las alusiones historiográficas sobre esta temática han sido cortas y fragmentadas.

Este trabajo se inscribe también dentro del marco del postconflicto que vive el país, y asume el reto de analizar el periodo de Independencia desde una nueva perspectiva que va más allá de la tendencia que ha primado en la historiografía colombiana de valorar la guerra, los acontecimientos del campo de batalla, las tácticas militares con la recurrente apología al heroísmo militar. La nueva apuesta apunta entonces a examinar este proceso de emancipación teniendo en cuenta su complejidad y enfatizar en la negociación y en la búsqueda de la paz que se exploraron durante estos años. La esperanza en torno a este nuevo

${ }^{18}$ Clément Thibaud, República en armas. Los ejércitos bolivarianos en la guerra de Independencia en Colombia y Venezuela (Bogotá: Planeta-Ifea, 2003), 475.

${ }^{19}$ José Manuel Restrepo, Historia de la Revolución, tomo 3: 88.

20 “Documentos varios", (1820), AGN, Sección República, Fondo Secretaría de Guerra y Marina, tomo 325, f. 920r; Cartas Santander-Bolívar 1820-1822 (Bogotá: Biblioteca de la Presidencia de la República, 1988), tomo 3: 76; Roberto Cortázar (comp.), Cartas y Mensajes, vol. I2: 423. 
enfoque es generar algunas claves que a manera de antecedente sirvan para comprender los procesos posteriores de reconciliación vividos a lo largo de la convulsionada vida republicana.

La investigación se elaboró con fuentes primarias de información, tales como: documentos de archivo, cartas cruzadas entre autoridades políticas y militares, memorias, crónicas, informes oficiales, diarios de campaña y artículos de prensa de la época.

\section{Los avatares del proceso de delimitación}

Conforme a lo estipulado en el tratado de Trujillo, el general Bolívar nombró al coronel Francisco Alcántara para que avisara al regimiento republicano del sur sobre la suspensión de las hostilidades ${ }^{21}$ con el fin de abrir paso al trazado de límites. A Alcántara se le previno de que debía persuadir a aquellos oficiales para que las demarcaciones se ajustaran a partir de las posiciones que ocupaban en ese momento las tropas, de tal modo que se facilitara la comunicación interna teniendo en cuenta además la buena fe que debía imperar en este proceso, pero sin llegar a exponerse a eventuales engaños por parte del enemigo y, también, se le recalcó la importancia de que la línea divisoria fuera bien marcada y conocida para que nadie pueda ignorarla 22 .

No obstante, en aras del juego estratégico, Bolívar impartió pocos días después instrucciones para dilatar la notificación del armisticio, tiempo que debía ser aprovechado por las huestes republicanas para ganar terreno y alistarse mejor. Para ello, sugirió hacer uso de algunos artificios, como: hacer perder el pliego notificativo, aducir que el conductor había enfermado o que el general Manuel Valdés, a la sazón jefe del Ejército del Sur, alegara que no estaba sujeto a las órdenes del vicepresidente Santander en esa área del sur ${ }^{23}$.

A mediados de diciembre, tanto Bolívar como Santander seguían esperanzados en que, si a Valdés le iba bien en la campaña militar que estaba adelantando en ese momento, podía recibir la notificación en Pasto y preparar mejor la arremetida contra Quito ${ }^{24}$. Sin embargo, los infranqueables escollos en

${ }^{21}$ Cartas Santander-Bolivar, tomo 3: 74.

${ }^{22}$ Roberto Cortázar (comp.), Correspondencia dirigida al general Santander (Bogotá: Academia Colombiana de Historia, 1969), vol. 3: 271-272.

${ }^{23}$ Archivo Santander (Bogotá: Águila Negra Editorial, 1916), tomo 5: 325.

24 “Representaciones varias” (Bogotá, 1820), AGN, Sección República, Secretaría de Guerra y Marina, tomo 332, f. 686r. 
el paso del Juanambú y la tenaz resistencia ejercida por las guerrillas del Patía alejaron esta oportunidad de avance para las huestes patriotas.

Bolívar era consciente de que el tratado suscrito en Trujillo no había considerado en toda su magnitud el panorama que se vivía en el sur en donde la tarea de demarcación era mucho más dispendiosa por sucesos extraordinarios como la revolución acaecida el 9 de octubre de 1820 en la ciudad de Guayaquil, hecho que se le imputó al gobierno de Colombia como un acto premeditado y de mala $\mathrm{fe}^{25}$. Por ello, pensaba que, para hacer viable la suspensión de armas, era imprescindible una modificación en el tratado para que fuera aplicable a las circunstancias regionales de tal modo que se asegurara que los guayaquileños quedaran bajo amparo del gobierno colombiano ${ }^{26}$. El presidente de Quito, don Melchor de Aymerich, rechazó enfáticamente esta pretensión bajo el argumento de que Guayaquil dependía del virreinato del Perú en materia de jurisdicción política.

A principios de enero, el general Antonio José de Sucre, quien había fungido como negociador en Trujillo, fue nombrado por unos cuantos días como nuevo comandante del Ejército del Sur. Tan pronto asumió sus funciones, se percató de la importancia de estos cuatro meses de tregua con miras a aliviar las condiciones de las tropas e infundirles algo de instrucción y disciplina, pues era desoladora su condición, agobiadas por las enfermedades y las deserciones, ya de nivel crítico $^{27}$. La idea era inspirarles ánimo y ponerlas en estado ofensivo para encarar la arremetida definitiva hacia Pasto y Quito. Se pidió de manera urgente la colaboración del gobierno central para el envío de todo el apoyo posible con el fin de cumplir estas metas.

En los momentos previos a la fijación de la línea divisoria, al interior del bando republicano se escucharon voces de incertidumbre. El coronel Pedro Murgueitio veía con bastante desconcierto cómo las tropas patriotas habían

${ }^{25}$ Esta insurrección benefició en gran forma los intereses del bando republicano pues se privó a España del único puerto que tenía sobre esa parte sur de la costa pacífica y quedó a la deriva la armada realista que operaba sobre esas aguas. Con la toma de esta plaza se emprendieron acciones progresivas para estrechar el cerco sobre la ciudad de Quito. Roberto Ibáñez, "El Armisticio”, en Historia de las Fuerzas Militares de Colombia, ed. Álvaro Valencia Tovar (Bogotá: Editorial Planeta, 1993), tomo 1 [El Ejército]: 350.

${ }^{26}$ Cartas Santander-Bolivar, tomo 3, 86.

${ }^{27}$ Cortázar, Correspondencia, vol. 12: 293. 
sido forzadas a evacuar parte del territorio ocupado con tanto sacrificio al sur de Popayán ${ }^{28}$.

La revolución espontánea ocurrida en la ciudad de Maracaibo el 28 de enero atizó la incertidumbre y puso en peligro el acuerdo firmado en Trujillo. Mientras tanto, el vicepresidente Santander le reiteró al general ManuelValdés que hiciera todo lo posible para atravesar el Juanambú antes de que llegaran los comisionados oficiales a difundir los tratados ${ }^{29}$. Aunque se cumplió este propósito, den el intento de ataque sobre Pasto los republicanos se tropezaron con una férrea resistencia y sufrieron una contundente derrota el 2 de febrero en la batalla de Genoy, en la que tuvieron 320 bajas y más de un centenar de dispersados, ante lo cual Valdés debió replegarse hacia Popayán con los restos de su vapuleada tropa ${ }^{30}$.

La delimitación quedó a cargo del coronel republicano Antonio Morales y, por el lado español, fue designado el teniente coronel José Moles ${ }^{31}$. Ambos llegaron a Pasto el 10 de febrero y pudieron constatar la positiva acogida que había tenido la idea del armisticio en el comandante militar Basilio García. No sucedió lo mismo con el pueblo pastuso, el cual, según los reportes, estaba muy seguro de la superioridad militar española y, por ello, creía innecesario el tratado, sobre todo, por el hecho de que se habían filtrado algunos documentos del ejército republicano en los que quedaban en duda las intenciones pacifistas de este bando ${ }^{32}$. No obstante, ingentes fueron los esfuerzos de las autoridades

${ }^{28}$ Biblioteca Nacional de Colombia (BNC), Fondo Archivo Histórico Restrepo, Fondo I, vol. 15, pieza $8, f .222 \mathrm{v}$.

${ }^{29}$ Cortázar (comp.), Cartas y mensajes, vol. 2, 445.

${ }^{30}$ Soledad Acosta de Samper, Biografía del general Joaquín Acosta (Bogotá: Librería Colombiana, 1901), 61. En su reporte, el comandante Basilio García calculaba que, de 1.200 hombres que componían las fuerzas republicanas, se habían registrado 360 bajas, principalmente del batallón Guías y del batallón Albión, se decomisaron, como material de guerra, 500 fusiles, 200 lanzas y 20 cajas de municiones. Mientras que el balance al interior de las fuerzas españolas, conformadas principalmente por pastusos e indios, era de 25 muertos y 60 heridos. BNC, Archivo Histórico Restrepo, Fondo I, vol. 24, pieza 24, ff. 226r-234r.

31 "Comunicación sobre la visita de los comisionados españoles para intimar el armisticio de Trujillo" (Popayán, 1821), AGN, Sección República, Fondo Negocios Administrativos, tomo 6 f. 639r; "Carta enviada al cabildo de Cartago sobre ratificación del tratado de armisticio" (Cartago, 1821), Archivo Central del Cauca (ACC), Sala Independencia, Civil II-17 Gobierno, signatura 6802 , ff. $3 \mathrm{r}-6 \mathrm{v}$.

${ }^{32}$ Guillermo Plazas Olarte, "Historia Militar", en Historia extensa de Colombia (Bogotá: Ediciones Lerner, 1970), vol. 18, tomo 3: 274; José Manuel Groot, Historia eclesiástica y civil de Nueva Granada (Bogotá: Editorial de Medardo Rivas, 1889), tomo 4: 137. 
españolas con miras a persuadirlos de las ventajas y la importancia de la tregua ${ }^{33}$. El obispo de Popayán, don Salvador Jiménez de Enciso, dirigió un mensaje a los pastusos para apaciguar sus ánimos; era la primera vez que mostraba una actitud conciliadora. Don Basilio hizo lo propio con una proclama en la que exhortaba a confiar en sus autoridades, las cuales tenían a su vista los oficios del general Pablo Morillo en los que se confirmaban los acercamientos de paz entre las partes ${ }^{34}$.

A la fecha del 16 de febrero no se había definido aún la línea divisoria. Por estos días, Sucre creía que el río Mayo sería una buena referencia, opinión que era compartida por el vicepresidente Santander porque abría la esperanza de contar con recursos que escaseaban en el territorio comprendido entre aquel afluente y el Juanambú ${ }^{35}$. Sucre recibió instrucciones a finales de febrero para retirarse de la zona y alistar los batallones Santander, Albión y Guías con los cuales tenía que emprender el ataque por mar hacia la ciudad de Guayaquil como estrategia alterna para conquistar Quito. El general venezolano Pedro León Torres asumió el 19 de este mes las riendas del Ejército del Sur en reemplazo de Valdés.

Los delegados se dirigieron luego a la ciudad de Quito, que sería la sede de las conversaciones. Como lo relató el comisionado Morales, fue recibido en la casa de Aymerich con las mayores atenciones y expresiones de amistad, sentado a la mesa con abundancia de viandas y bebidas. Quedó satisfecho con la actitud del obispo, del clero, del cabildo, de las autoridades militares y de los colegios quiteños. Amable se había comportado también la muchedumbre concurrente de la que alcanzaron a escuchar algunos vivas a la Patria ${ }^{36}$. En este ambiente de cordialidad, el 21 de febrero el par de comisionados, en presencia de Aymerich trazaron nueve puntos como lineamientos básicos que serían avalados por ambos gobiernos.

En reconocimiento al territorio que ocupaba cada ejército contendiente y con el fin de evitar confrontaciones violentas, se decidió, primero que todo,

33 "Armisticio", Gazeta de la ciudad de Bogotá, N. 85 (Bogotá: Imprenta del Estado por Nicomedes Lora, marzo 11 de 1821), 262; Santiago Arroyo, Apuntes históricos sobre la Revolución de la Independencia de Popayán (Bogotá: Ediciones Virtual, 2010), 140.

${ }^{34}$ Archivo Santander, vol. 6, 55-56.

${ }^{35}$ Roberto Cortázar (comp.), Correspondencia dirigida, Vol. XII, 298-299; Cortázar (comp.), Cartas y mensajes, vol. $3,86$.

36 “Ejército del Sur”, (1821), AGN, Sección República, Fondo Secretaría de Guerray Marina, tomo 7, f. 538 r. 
marcar como línea divisoria el río Mayo (ver Figura N. ${ }^{\circ}$ ). El otro punto de acuerdo fue el desarme de todas las guerrillas y el canje de prisioneros. No obstante, el nudo gordiano de las negociaciones fue Guayaquil. Los republicanos defendieron su derecho sobre esta ciudad recientemente liberada y consideraron que sería una violación al armisticio cualquier represalia fraguada por los españoles desde Quito o Perú. Los españoles, por su parte, fueron muy enfáticos en insistir que carecían de competencia para tratar el tema de Guayaquil dado que esta ciudad hacía parte de la jurisdicción del Perú.

\section{Figura N. ${ }^{\circ} 1$}

Demarcación del territorio asignado a los republicanos y a los españoles para el armisticio en las provincias del sur, según el acuerdo firmado en Quito el 21 de febrero de 1821(Ver figura 01)

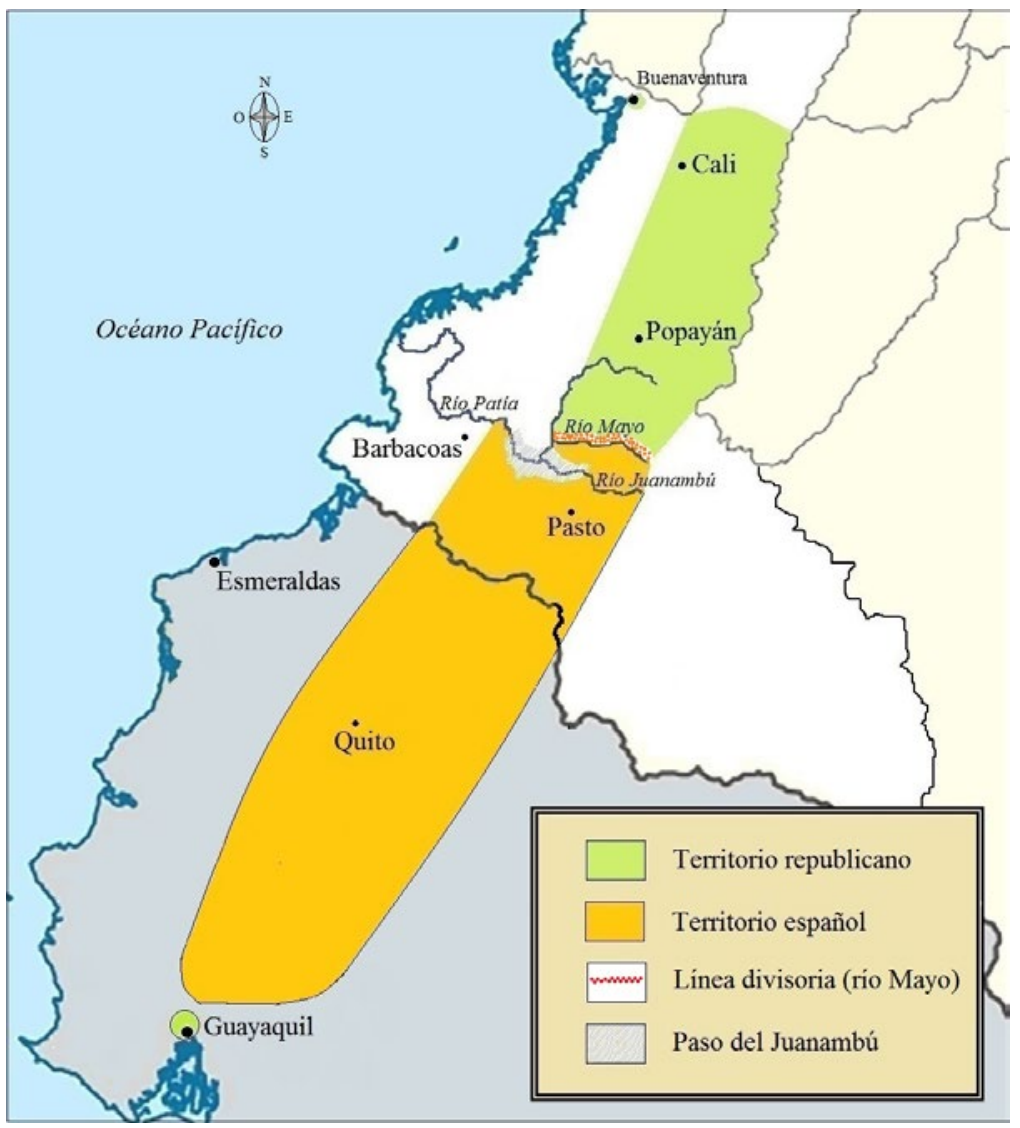

Fuente: AGN, Sección República, Fondo Secretaría de Guerra y Marina, tomo 334, ff. 382r-383v. 
Al cabo de cinco días, el mismo Aymerich se encargó de enviar al presidente Simón Bolívar copia del acuerdo para su respectiva refrendación. Sobre la línea divisoria, reiteró que su gobierno había propuesto inicialmente la ciudad de Popayán y el río Cauca, marcando la línea en Cabuyal cerca del Tambo y La Horqueta ${ }^{37}$ en cercanías de Timbío. Esta propuesta incluía el partido de Almaguer y el Patía para el bando español, lo cual consideró más que pertinente en vista de que los guerrilleros patianos eran propensos a hacer la guerra a la desbandada y sin jefe ni subordinación, situación que podía generar complicaciones y desavenencias entre las partes. Finalmente, reconoció haber cedido en sus pretensiones al ordenar el repliegue de las guerrillas que ocupaban el costado norte del río Mayo ${ }^{38}$.

Por su parte, el comisionado Morales había insinuado trazar la línea por el río Juanambú ${ }^{39}$, pero aceptó finalmente el río Mayo en vista de que entre estos dos ríos era muy corta la distancia y el terreno, escaso de ganados, caballos y víveres para la guerra ${ }^{40}$. Reconoció sin mayores ambages que Cuenca había sido ocupada nuevamente por los realistas y que, en la provincia de los Pastos, ningún pueblo había proclamado su libertad, salvo algunos grupúsculos aislados que, por sus ideas republicanas, debieron refugiarse en los montes ${ }^{41}$.

En aras del consenso, Aymerich optó por no elevar reclamo ante dos hechos que para él eran reprochables: el avance del general Valdés hacia el Sur, cuando ya estaba avisado del acuerdo, y la llegada del general Sucre para reforzar las tropas en flagrante violación al artículo 13 del armisticio. Reiteró la buena fe del gobierno monárquico al recordar cómo, después del triunfo obtenido en la batalla de Genoy, sus huestes habían decidido no invadir Popayán y el valle del Cauca al percatarse de la oportunidad de llegar a una tregua entre las

\footnotetext{
${ }^{37}$ Hoy municipio de Dolores en el departamento del Cauca.

${ }^{38}$ AGN, Sección República, Fondo Secretaría de Guerra y Marina, tomo 334, ff. 381r-383v.

${ }^{39}$ En realidad, algunos sectores del bando republicano pensaban que hubiera sido más ventajoso que la línea se trazara al otro lado de este afluente, tal como lo recomendó el general Valdés. Manuel Antonio López, Recuerdos históricos del coronel Manuel Antonio López, ayudante del Estado Mayor General Libertador, Colombiay Perú 1819-1826 (Bogotá: Imprenta Nacional, 1955), 37; "Armisticio", Gazeta de la ciudad de Bogotá, N. o 88, abril 1. de 1821, 273.

40 “Correspondencia militar Ejército del Sur” (Popayán, 1821), ACC, Sala Independencia, Militar I-4 Correspondencia, signatura 6793, f. 38r.

41 "Ejército del Sur", (1821), AGN, Sección República, Fondo Secretaría de Guerra y Marina, tomo 7, f. 538 r.
} 
partes $^{42}$. El estamento eclesiástico contribuyó también a aclimatar el ambiente de reconciliación. El 22 de febrero, el obispo Jiménez de Enciso publicó en Pasto un edicto con su decisión de que, bajo el marco del armisticio, suspendía las excomuniones y demás censuras eclesiásticas ${ }^{43}$ emitidas contra los "desafectos" de la causa monárquica.

A fin de cuentas, esta división territorial les permitió a los republicanos contar con la ciudad de Cali como epicentro de provisión de recursos y con Popayán como sede del cuartel general, mientras que Pasto quedó confirmada como sede central de las mesnadas españolas con el valioso respaldo político y militar de la aliada ciudad de Quito.

Una vez definida la línea divisoria, el general Torres dictó el 15 de marzo una serie de instrucciones al teniente coronel Pedro A. García para que se encargara de la seguridad al interior de los límites del territorio republicano. Antes que nada, debía situarse en algún paraje contiguo a la línea divisoria que le permitiera advertir los puntos susceptibles de ataque y vigilar cualquier infracción por parte de la guarnición de Pasto. En caso de agresión, debía resistirla siempre y cuando las fuerzas contrarias no fueran superiores, caso en el cual había que replegarse hacia Popayán. Una copia del armisticio le fue entregada para garantizar su cabal observancia. Igualmente debía brindar buen trato a los habitantes, inspirándoles seguridad y confianza, respetándoles todos sus derechos y esforzándose por desmentir cualquier opinión contraria al sistema republicano.

Para cada pueblo debía nombrar un comandante militar. Los alcaldes ordinarios y demás jefes políticos locales ubicados a este lado del río de Mayo debían suministrar auxilios para la subsistencia de la tropa. Estas autoridades civiles quedaron prácticamente supeditadas al control de las autoridades militares, pues debían estar en permanente contacto con ellas para evitar alteraciones del orden público o excesos en sus funciones, y aplicar los correctivos y sanciones en caso de omisión o resistencia ${ }^{44}$.

Bajo el marco normativo del armisticio, el comandante García solicitó garantías para que las tropas españolas que estaban en territorio dominado

42 “Comandancia del Sur”, (1821), AGN, Sección República, Fondo Secretaría de Guerra y Marina, tomo 334, ff. 400r-401v.

43 “Ejército del Sur”, (1821), AGN, Sección República, Fondo Secretaría de Guerra y Marina, tomo 7, f. 525r; Cortázar (comp.), Correspondencia dirigida, vol. 13: 96.

44 “Ejército del Sur”, (1821), AGN, Sección República, Fondo Secretaría de Guerray Marina, tomo 7, ff. 551r-1152r. 
por los republicanos pudieran regresar a su zona. Por ello, tramitó pasaportes para el capitán Hermenegildo Mendiguren, el teniente Joaquín González y sus tropas, que patrullaban por Anserma, en el Valle del Cauca, para que pudieran retornar al otro lado del río Mayo a reencontrarse con el resto de la división española ${ }^{45}$.

Al oficial español Sebastián de la Calzada se le expidió a finales de marzo salvoconducto para transitar por territorio republicano, aunque el vicepresidente Santander ordenó que, una vez cruzara la línea de Mayo, se designara un oficial de toda confianza que venga con él y le espíe sus operaciones. El 27 de abril, Calzada fue nombrado para reemplazar al coronel Moles como comisionado del lado español ${ }^{46}$.

\section{El tratado en vilo: infracciones y confusiones}

Durante el tiempo de armisticio sucedieron incidentes y roces que pusieron en riesgo este tratado. Frecuentes fueron las recriminaciones mutuas y los argumentos que pretendían justificar que se había obrado de buena fe. De alguna forma, estos hechos fueron un ingrediente adicional de desconfianza e incertidumbre entre las dos fuerzas beligerantes y permitieron comprobar la extrema vulnerabilidad de este proceso de tregua.

Aunque el artículo $4 .{ }^{\circ}$ del armisticio había estipulado la disolución inmediata de todos los grupos guerrilleros, a decir verdad, los combatientes del Patía ${ }^{47}$ habían logrado tal nivel de arraigo y radicalismo que fue prácticamente imposible su total desmantelamiento. Con anticipación, los dos comisionados habían enviado comunicaciones a finales del mes de enero a los jefes del Patía invitándolos a cesar toda hostilidad ${ }^{48}$. No obstante, Aymerich estaba convencido de que estos grupos irregulares no debían desarmarse antes del proceso de demarcación.

\footnotetext{
45 “Comisión del general Sucre a Guayaquil”, (1821), AGN, Sección República, Fondo Secretaría de Guerra y Marina, tomo 76, ff. 18r-23r.

46 “Ejército del Sur”, (1821), AGN, Sección República, Fondo Secretaría de Guerra y Marina, tomo 7, ff. 615r, 640r.

${ }^{47}$ Desde inicios del periodo independentista, los jefes realistas, bajo el influjo del obispo Jiménez de Enciso, habían logrado movilizar estas fuerzas irregulares conformadas por indios, negros y mestizos. Francisco Zuluaga, Guerrilla y sociedad en el Patía. Una relación entre el clientelismo político y la insurgencia social (Santiago de Cali: Universidad del Valle, 1993), 73.

${ }^{48}$ Cortázar (comp.), Correspondencia dirigida, vol. 12, 295.
} 
Por su parte, el bando republicano había tomado sus propias prevenciones. Cuando asumió el mando de la División del Sur, al general Torres se le advirtió que, en caso de suscitarse algún acto de hostilidad por parte de aquellos grupos irregulares, debía verificarse el hecho y exigir las explicaciones correspondientes. Si había reincidencia, quedaba autorizado para atacar siempre y cuando contara con la suficiente capacidad ofensiva. Si estaba en desventaja operativa, debía entonces elevar el reclamo y simultáneamente coordinar acciones para perseguir a los agresores ${ }^{49}$.

Al parecer, la intención de los españoles fue tratar de cubrir a través de sus fuerzas guerrilleras la mayor extensión de terreno, mientras no se concretara la delimitación de la línea fronteriza entre ambos bandos. El 1. ${ }^{\circ}$ de febrero, el coronel republicano Antonio Obando, jefe del cuartel divisionario de Popayán, recibió información de que el teniente coronel Simón Muñoz, comandante de las guerrillas del Patía, se aproximaba a esta ciudad con el fin de invadirla. Ante esta circunstancia, Obando le comunicó a Muñoz los términos del armisticio y le envió copias del tratado y del acuerdo de regularización de la guerra, advirtiéndole que era voluntad de los republicanos mantener la paz, pero que también estarían en posición de reaccionar en caso de cualquier acometida.

Muñoz finalmente accedió el 3 de febrero a firmar en el sitio de Calicanto el cese de hostilidades con el coronel Obando y con el oficial Tomás Cipriano de Mosquera ${ }^{50}$, comandante de la plaza de Popayán. Al día siguiente, el oficial español cumplió con lo pactado e inició su retirada hacia el Patía, y reiteró su compromiso de no atacar a Popayán ni interceptar comunicaciones ${ }^{51}$. No obstante, los oficiales republicanos no dejaron de estar alerta pues desconfiaban de estas promesas y se declaraban temerosos, pues la plaza estaba aún indefensa y, por eso, se impartieron órdenes para reforzarla ${ }^{52}$. Días más tarde, el comandante García recriminó a Muñoz por haberse precipitado a firmar el cese de hostilidades sin su previa anuencia, pues nunca debió haberse detenido

49 "Correspondencia del Vicepresidente”, (1821), AGN, Sección República, Fondo Secretaría de Guerra y Marina, tomo 329, f. 129r.

${ }^{50}$ Este oficial ocuparía años más tarde la presidencia de la República.

51 “Ejército del Sur”, (1821), AGN, Sección República, Fondo Secretaría de Guerra y Marina, tomo 7, f. 885 r.

${ }^{52}$ Cortázar (comp.), Correspondencia dirigida, vol. 4: 138-139. 
en su intención de tomar a Popayán, con lo cual se hubiera alcanzado a negociar como línea divisoria el río Cauca ${ }^{53}$.

Al llegar el general Valdés el día 12 de febrero a Popayán denunció el "procedimiento escandaloso" de las guerrillas de interceptar las comunicaciones e impedir el paso a las tropas republicanas que se replegaban hacia esa ciudad. La desconfianza y la tensión eran evidentes en momentos en que apenas 500 hombres mantenían la defensa del cuartel general ${ }^{54}$. En el camino que conectaba con Mercaderes, el mismo Valdés había sido hostilizado. Otro ataque sucedió en el sitio de Guacimal, en cercanías al Patía, ante lo cual hubo necesidad de recordar a Muñoz sobre los alcances del armisticio.

De igual modo, se reportó que una partida de 40 hombres que acompañaban al teniente coronel republicano Pedro Murgueitio había sido insultada, saqueada y despojada de sus armas. En esta acción las guerrillas asesinaron a cinco hombres e hicieron prisioneros a otros más. En total, los agresores lograron apoderarse de 50 fusiles. A este jefe guerrillero también se le sindicó de difundir noticias falsas sobre la supuesta decisión de los patriotas de reanudar las hostilidades ${ }^{55}$.

En el artículo 3. del acuerdo regional suscrito en Quito el 21 de febrero para trazar la línea divisoria, se reiteró lo acordado en Trujillo y, por consiguiente, se dispuso el desarme de todas las guerrillas realistas del Patía. Aquellas que hicieren parte de la tropa regular, debían retroceder hasta el cuartel general de Pasto ${ }^{56}$. Sin embargo, este convenio firmado en Quito no logró detener las fricciones y los incidentes. En carta enviada el 7 de marzo, el comandante Basilio García reconoció que algunas partidas de guerrilleros habían cometido ataques, aunque las justificó por no haber sido notificadas oficialmente de la demarcación de la línea divisoria. De todos modos, prometió castigar a los infractores, aunque reconoció ciertas dificultades para controlar todas sus fuerzas desde su comando central en la ciudad de Pasto. Por lo pronto,

53 “Correspondencia Ministro de Guerra”, (1821), AGN, Sección República, Fondo Secretaría de Guerra y Marina, tomo 329, f. 582r.

${ }^{54}$ Cortázar (comp.), Correspondencia dirigida, vol. 9: 142.

55 “Ejército del Sur", (1821), AGN, Sección República, Fondo Secretaría de Guerra y Marina, tomo 7, ff. 513vr-516v.

56 "Comandancia del Sur”, AGN, Sección República, Fondo Secretaría de Guerra y Marina, tomo 334, f. 382r. 
dio potestad a las huestes patriotas de repeler a los invasores, aunque pidió mantener la calma para resolver estos inconvenientes ${ }^{57}$.

Por su parte, Santander instó a Valdés a acudir con la máxima firmeza ante las más altas instancias, así fuera ante el general del Ejército Expedicionario español $o$ ante la misma Corte de Madrid para exigir las respectivas disculpas a insultos de tal naturaleza ${ }^{58}$. Exigió, además, la devolución de los fusiles incautados y algunos papeles oficiales. No obstante, don Basilio solo devolvió los baúles hurtados al general Valdés, 15 fusiles y 5 carabinas.

Otra de las quejas fue expuesta a finales de febrero por el general Sucre cuando informó que las dos compañías de Aragón, pese a que habían sido informadas en Taminango sobre el armisticio, en vez de retroceder a Buesaco, procedieron a avanzar hacia Mercaderes en territorio republicano en lo que se consideró una clara provocación. Sucre censuró además la actitud del capitán guerrillero José Naudín quien, sabiendo de la firma del armisticio cuando entraba a las montañas de Berruecos, traspasó la línea de Mayo y expulsó a un comisionado republicano que iba a reclamar 50 reses que habían sido robadas por las tropas guerrilleras. Por estos días, este alto oficial republicano se declaró cansado de las reiteradas hostilidades de las guerrillas y confesó haberse llenado de mucha paciencia para evitar un rompimiento anticipado de la tregua ${ }^{59}$.

Un punto adicional de animadversión entre las partes fue la decisión de al menos 12 oficiales guerrilleros de cambiar de bando, entre quienes figuraban reconocidos comandantes como el coronel Simón Muñoz, el teniente coronel José María Obando ${ }^{60}$ y el capitán José Naudín. Los republicanos estimularon y acogieron estas conversiones, pero, como era previsible, los españoles no recibieron con buen ánimo estas felonías de sus antiguos aliados de lucha y no dudaron en aplicar severas represalias, como fue el caso de la pena de muerte a Muñoz ${ }^{61}$.

57 “Ejército del Sur”, (1821), AGN, Sección República, Fondo Secretaría de Guerray Marina, tomo 7 , f. $545 \mathrm{r}$.

${ }^{58}$ Cortázar (comp.), Cartas y mensajes, vol. 3, 50, 415, 424.

59 “Comisión del general Sucre a Guayaquil”, (1821), AGN, Sección República, Fondo Secretaría de Guerra y Marina, tomo 76, f. 28r.

${ }^{60}$ Años más tarde Bolívar lo ascendió al grado de general y, entre 1853 y 1857, ocupó el cargo de presidente de la República.

${ }^{61}$ "Ejército del Sur", (1821), AGN, Sección República, Fondo Secretaría de Guerra y Marina, tomo 7, ff. 586r, 623r; Luis Martínez Delgado y Sergio Elías Ortiz (comp.), Epistolarioy documentos oficiales del general José María Obando (Bogotá: Academia Colombiana de Historia, 1973), tomo 1: 19; José María Obando, Apuntamientos para la historia (Bogotá: Editorial Bedout, 
Las revoluciones espontáneas sucedidas en Guayaquil y Maracaibo se convirtieron en dos factores que menguaron la confianza entre las partes. El 28 de marzo, el vicepresidente Santander impartió instrucciones al jefe del Ejército del Sur para que acogiera a los pueblos y provincias que quisieran pertenecer a la República. Así lo había dispuesto el general Bolívar al reiterar que el armisticio no excluía esa posibilidad. Lo que sí debía evitar el general Torres era ser él el directo seductor ${ }^{62}$.

En los primeros días de abril, el comandante Basilio García expresó su rechazo al filtrarse la noticia sobre la travesía marítima del general Sucre que tenía como propósito auxiliar a la junta de gobierno de Guayaquil. Sobre este punto, el general Torres le aclaró que este apoyo no estaba proscrito ya que esta ciudad había decidido libremente alinderarse al gobierno republicano, el cual estaba legítimamente autorizado para brindar ayuda económica siempre y cuando no se recurriera al uso de las armas ni se pisara territorio bajo control español $^{63}$. Aymerich tampoco ocultó su inconformidad sobre este tema, sobre todo porque el levantamiento popular guayaquileño había ocurrido después de la firma del armisticio y cualquier adhesión política solo sería válida bajo nuevos tratados en los que debía intervenir el virrey del Perú, en cuya jurisdicción se hallaba aquella ciudad ${ }^{64}$.

Una nueva imperfección salió a flote en relación con el acuerdo de demarcación, cuando se advirtió que nada se había dispuesto sobre la costa pacífica. Vale recordar que pocos días antes de notificarse el armisticio, los republicanos lograron dominar Barbacoas y Esmeraldas. El problema se suscitó a principios de marzo cuando los españoles denunciaron las hostilidades cometidas por las tropas republicanas en esta última ciudad, de donde se llevaron varios esclavos de minas.

En medio de esta tensión, el comandante Basilio García impartió instrucciones el 19 de marzo al subteniente Manuel Ortiz para que pasara a la ciudad de Barbacoas y, tan pronto avistara las huestes republicanas, presentara en una vara un pañuelo blanco símbolo de la paz y debía entrar en diálogo con el

1972), 33, 47; Diego Castrillón Arboleda, Manuel José Castrillón (biografía y memorias) (Bogotá: Biblioteca Banco Popular, 1971), tomo 1:, 196-197.

${ }^{62}$ Cortázar (comp.), Cartas y mensajes, vol. 3, 90.

${ }^{63}$ Cortázar (comp.), Correspondencia dirigida, vol. 13, 117; Archivo Santander, vol. 6, 208.

${ }^{64}$ Vicente Lecuna, Cartas del Libertador (Caracas: Fundación Vicente Lecuna, 1965), tomo 3: 10-12; "Ejército del Sur”, (1821), AGN, Sección República, Fondo Secretaría de Guerray Marina, tomo 7 , f. 642r. 
jefe para convenir la línea divisoria que abarcara algunos puntos de la costa ${ }^{65}$. Sin embargo, esta demarcación no se llevó a cabo.

El general Torres adujo que muy poco podía hacer en relación con el incidente ocurrido en Esmeraldas, pues el convenio suscrito en Quito nada había contemplado en materia de demarcación, con el antecedente de que históricamente había sido muy difusa la línea que separaba esas jurisdicciones costeras de las provincias interiores de los Pastos y Quito. Sin embargo, Torres se comprometió a recomendarles a sus oficiales en Esmeraldas que operaran únicamente dentro de los límites de su territorio. Las recriminaciones fueron mutuas, pues se denunció que algunas cuadrillas realistas se estaban movilizando por el río Micay en espacio republicano, en donde habían cometido la indelicadeza de llevarse varios esclavos. Como solución, se propuso demarcar lo antes posible la línea divisoria entre ambos ejércitos ${ }^{66}$, pero, al parecer, nunca se llegó a un acuerdo.

\section{El fin del armisticio y la reanudación de la guerra}

Previendo quizás lo vulnerable que era el armisticio, desde su comienzo las cabezas visibles de ambos bandos fueron enfáticas en prevenir a sus subordinados y a sus tropas en terreno para que siempre estuvieran muy preparados para el momento en que expirara el cese de hostilidades. El envío de tropas republicanas a Guayaquil, los vacíos en materia de demarcación de límites y los reiterados reclamos por infracciones al tratado fueron factores que daban cuenta del alto nivel de vulnerabilidad en esos tiempos de tregua por los lados del Sur.

Finalmente, el 10 de marzo, Bolívar comunicó al general en jefe español don Miguel de La Torre ${ }^{67}$ que, recurriendo al artículo 12 del armisticio de Trujillo, se veía forzado a reemprender anticipadamente las hostilidades debido a la falta de recursos para sostener el ejército y a las reducidas esperanzas de entablar las negociaciones de paz, pues durante estos meses de tregua no se había conseguido que los enviados españoles, el brigadier de la Armada José

65 “Comisión del general Sucre a Guayaquil”, (1821), AGN, Sección República, Fondo Secretaría de Guerra y Marina, tomo 76, f. 509r.

66 “Ejército del Sur", (1821), AGN, Sección República, Fondo Secretaría de Guerray Marina, tomo 7, ff. 610r-611v.

${ }^{67}$ Este general asumió el mando supremo de las fuerzas militares españolas que operaban en Venezuela y en buena parte de Colombia tras la dimisión del general Pablo Morillo, quien regresó a España a principios de enero de 1821. 
Sartorio y el capitán de fragata Francisco Espelius, se sentaran a dialogar con los delegados republicanos José Rafael Revenga y José Tiburcio Echeverría ${ }^{68}$. En razón a estos impasses, Bolívar informó que los 40 días convenidos en el artículo 12 del armisticio empezarían a contar desde el momento mismo en que fuera recibida esa notificación, que se estimaba lo fuera en un plazo no mayor a 10 días. Así entonces, se calculaba que el 1.. de mayo podía romperse definitivamente la tregua ${ }^{69}$.

Pocos días antes de que Bolívar oficializara a su contraparte la terminación del armisticio, ya el secretario de Guerra, don Pedro Briceño, había instado estratégicamente al vicepresidente Santander para que advirtiera, a los jefes militares de la costa caribe y del Sur, de que estuvieran atentos a ganar en esta coyuntura el mayor terreno posible ${ }^{70}$. Sobre todo, se les recomendó estar preparados para defenderse, por si el enemigo incurría en alguna traición al intentar un golpe de sorpresa.

En desarrollo de la referida orden, el 24 de marzo el vicepresidente Santander instó al general Pedro León Torres y al gobernador del Cauca, el coronel José Concha, para que, por medio de bando, avisaran a los pueblos sobre este rompimiento en tanto que el Ejército del Sur debía estar listo para obrar y superar cualquiera de las dificultades que habían retardado el avance más allá del paso del Juanambú, demora que había traído graves consecuencias para los planes republicanos ${ }^{71}$.

Pero, más allá de las directrices superiores, a nivel regional el objetivo era no precipitarse a tomar una decisión desfavorable, prepararse mejor y obtener ventajas para el reinicio de la guerra. Así, entonces, mientras que en la costa caribe se mantuvo vigente la fecha del 1. ${ }^{\circ}$ de mayo para la reanudación de las operaciones en vista de la evidente superioridad de los republicanos, en el sur la situación obligó a replantear la estrategia.

${ }^{68}$ José Félix Blanco, Documentos para la historia de la vida pública del Libertador (Caracas: Ediciones de la Presidencia de la República, 1978), vol. 7: 563-564.

69 "Copia impresa del decreto firmado por Francisco de Paula Santander, en donde el Libertador Presidente rompe el armisticio" (San Cristóbal, 1821), AGN, Sección República, Fondo Historia, tomo 3, f. 741r; Roberto Cortázar (Comp.), Cartas y Mensajes, Vol. III, 93-94, 425.

${ }^{70}$ Cortázar (comp.), Cartas y mensajes, vol. 3, 74.

71 “Comandancia General del Cauca. Correspondencia” (Bogotá, 1821), AGN, Sección República, Fondo Secretaría de Guerra y Marina, tomo 4, f. 487r; Cortázar (comp.), Cartas y mensajes, vol. $3,44,412$. 
Mediante una nota confidencial, el 30 de marzo, Santander urgió a los generales Torres y Sucre para que, si algún incidente inesperado los llenaba de temores para reanudar operaciones por estar en condiciones de desventaja, debían detener las comunicaciones notificatorias de cese de tregua ${ }^{72}$. Tanto Bolívar como Santander eran conscientes de que el jefe del Ejército del Sur no contaba aún con la suficiente capacidad militar para atacar a Pasto ${ }^{73}$, en tanto que el general Sucre tampoco estaba preparado para invadir Quito. La idea era que, en el momento indicado, ambos oficiales debían emprender simultáneamente sus campañas con el fin de acrecentar las posibilidades de éxito ${ }^{74}$.

La experiencia había demostrado que durante el armisticio los pueblos desafectos y varios líderes guerrilleros se habían inclinado hacia la causa republicana $^{75}$, por lo cual resultaba conveniente mantener la suspensión de armas mientras se ganaba más la opinión del valle del Patía y de los pueblos de Pasto. Así entonces, Torres no debía todavía anunciar la reanudación de las hostilidades explicándole a Aymerich que estaba a la espera de la respuesta de Bolívar a la consulta sobre si los seis meses del armisticio debían contar desde el 3 de febrero. Si ya había hecho el anuncio de rompimiento, debía retirarlo oficialmente bajo el argumento de que había recibido órdenes superiores porque se estaba negociando en Venezuela un nuevo armisticio $^{76}$. Este lapso sería valioso para evaluar la situación en Guayaquil, y el viaje del general Sucre, además de analizar el estado real de las fuerzas acantonadas en Popayán, para que el gobierno determinara finalmente cuál de las dos rutas ofrecía menos obstáculos con el fin de concentrar los esfuerzos adecuadamente. No obstante, Santander fue enfático en advertir que, si ocurría alguna circunstancia favorable, como una inusitada revolución en Quito, tanto Torres como Sucre podían acelerar el aviso de los 40 días previos para el rompimiento de la tregua.

${ }^{72}$ Cortázar (comp.), Cartas y mensajes, vol. 3, 94.

${ }^{73}$ Según el estado de fuerza presentado el 20 de abril, el Ejército del Sur al mando del general Torres contaba con un total de 1.146 hombres: 286 del batallón Cundinamarca, 268 del batallón Neiva, 306 del batallón del Cauca y 96 del batallón Guías. No obstante, alta era la cifra de enfermos y desertores. De las armas se contabilizaron 703 fusiles y 562 bayonetas. "Ejército del Sur", (1821), AGN, Sección República, Fondo Secretaría de Guerra y Marina, tomo 7,627 r.

${ }^{74}$ Cortázar (comp.), Correspondencia dirigida, vol. 13, 125.

75 “Ejército del Sur”, (1821), AGN, Sección República, Fondo Secretaría de Guerra y Marina, tomo 7, f. $617 \mathrm{r}$.

${ }^{76}$ Cortázar (comp.), Cartas y mensajes, vol. 3, 112. 
Lo cierto es que el general Torres ya había comunicado al comandante García la decisión de reanudar anticipadamente operaciones para el 1.ํㅡㄹ mayo. Sentimientos contrapuestos despertó esta noticia en Pasto, pues, por un lado, el oficial español expresó su lamento bajo el entendido de que no había sido culpa de los oficiales en terreno, sino de lo acordado por los máximos mandos militares en la frontera con Venezuela. Pero, por otro lado, relató cómo los habitantes de aquella ciudad habían reaccionado espontáneamente con gran alborozo, dando con ello una prueba más de su acendrado monarquismo ${ }^{77}$.

Torres acogió la sugerencia de Santander y, mediante carta dirigida el 21 de abril, propuso al presidente Aymerich posponer el fin de la tregua ${ }^{78}$. No obstante, este juego de órdenes y contraórdenes exacerbó mucho más la tensión y desconfianza entre las partes, e incrementó los rumores y las recriminaciones mutuas.

El mismo Torres se declaró confundido por estos cambios súbitos de decisiones en momentos cruciales, cuando don Basilio lo acusaba de mala fe por no haberle avisado oportunamente la orden de Bolívar y La Torre de romper la tregua para el día 1. ․ de mayo ${ }^{79}$. Aun con estas reservas, Torres aprovechó la ocasión para recriminar la actitud de los españoles de propagar noticias falsas y tendenciosas que informaban, por ejemplo, que el vicepresidente Santander había impartido instrucciones para saquear a Pasto y a Quito ${ }^{80}$. Se especulaba incluso que los españoles habían incendiado el paraje venezolano donde se había firmado el armisticio.

Aymerich y García se mostraron mucho más desconcertados con estas vacilaciones en el bando republicano y se sentían, además, indignados por la amenaza de la falsa noticia difundida ampliamente sobre la supuesta marcha que había emprendido el general Bolívar hacia estas tierras del Sur. El 12 de mayo, Aymerich respondió negativamente a la propuesta de aplazamiento bajo el argumento de que no había llegado a Quito ninguna noticia por parte de sus superiores, ni había recibido la visita de comisionados españoles que dieran cuenta del cambio de planes en relación con lo estipulado en el armisticio. Le recordó a Torres el cúmulo de antecedentes de violación del tratado, entre

\footnotetext{
77 “Ejército del Sur”, (1821), AGN, Sección República, Fondo Secretaría de Guerra y Marina, tomo 7, f. $649 \mathrm{v}$.

78 "Ejército del Sur", (1821), AGN, Sección República, Fondo Secretaría de Guerray Marina, tomo 7, f. 633 r.

${ }^{79}$ Cortázar (comp.), Correspondencia dirigida, vol. 13, 131.

${ }^{80}$ Cortázar (comp.), Correspondencia dirigida, vol. 13, 125.
} 
los cuales, el más grave era el auxilio a Guayaquil como táctica soterrada para invadir Quito.

No obstante, el alto funcionario español abrió una esperanza para admitir la propuesta de prolongación del armisticio, siempre y cuando salieran inmediatamente de Guayaquil las tropas republicanas de refuerzo. Su otro condicionamiento tenía un trasfondo estratégico, pues aspiraba a que el adversario cediera todo el territorio comprendido desde la línea divisoria del río Mayo hasta la población del Tambo, en inmediaciones de la ciudad de Popayán ${ }^{81}$. Estos dos requisitos fueron tajantemente rechazados el 24 de mayo por la alta oficialidad republicana ${ }^{82}$, ante lo cual las partes quedaron abocadas a retomar las hostilidades el 27 de mayo.

Bastantes temores sentía el mando republicano con la ruptura de la tregua, pues era indiscutible la superioridad militar de los dos más enraizados bastiones realistas, las ciudades de Pasto $^{83}$ y Quito, mientras que las tropas patriotas mostraban todavía un cuadro deplorable, aquejadas por la falta de recursos, la deserción y las bajas por las enfermedades.

Las huestes republicanas apostadas a lo largo de esta línea divisoria no ofrecían mucha seguridad, por lo que no quedó otra opción que replegarlas hacia el cuartel general de Popayán y, desde allí, intentar la máxima resistencia posible ${ }^{84}$. El desbalance de fuerzas evidenciado en esta coyuntura hizo que algunos combatientes patriotas se pasaran al bando español al perder las esperanzas de un triunfo remoto.

Desde el día 26 de mayo, se mandó redoblar la vigilancia militar y el trabajo de maestranza para la elaboración de lanzas. Para fortalecer la defensa en Popayán, hubo necesidad de levantar trincheras en los ángulos de las principales manzanas de la ciudad ${ }^{85}$. Mientras tanto, el vicepresidente Santander coordinaba acciones dirigidas a engrosar el pie de fuerza del Ejército

81 “Ejército del Sur”, (1821), AGN, Sección República, Fondo Secretaría de Guerray Marina, tomo 7, ff. 721r-722v; Memorias del General O'Leary, tomo 19, 38-39.

82 "Ejército del Sur", (1821), AGN, Sección República, Fondo Secretaría de Guerra y Marina, tomo 7, f. 702r; Cortázar (comp.), Cartas y mensajes, vol. 3, 195.

${ }^{83}$ Sobre el debate en torno al enraizado monarquismo de la ciudad de Pasto, véase: Carol Estefanía Guerrero Bucheli y Gerardo León Guerrero Vinueza, El honor en Pasto durante la Independencia. "La defensa de la santa causa" (Pasto: Universidad de Nariño, 2011), 151-156.

${ }^{84}$ Cortázar (comp.), Correspondencia dirigida, vol. 13, 142.

85 "Diario de operaciones del Ejército del Sur" (Popayán, 1821), AGN, Sección República, Fondo Secretaría de Guerra y Marina, tomo 329, ff. 610r-614v. 
del Sur: 300 reclutas enviados de Bogotá, 4 compañías del batallón Paya de Antioquia, 300 reclutas de las provincias de Socorro y Tunja, y 100 más de Honda, mientras que del depósito de Neiva fueron despachados 400 reclutas. Todo esto, sumado al envío de más de 15.000 pesos, suscitó en el general Torres la ilusión momentánea de contar con la capacidad para defenderse de la avanzada realista y emprender la ofensiva sobre Pasto y Quito ${ }^{86}$. Un total de 200 hombres se destinaron para reforzar la amenazada guarnición de Barbacoas ${ }^{87}$.

En pocos días, las huestes realistas invadieron el valle del Patía y, el 12 de junio, iniciaron el asedio sobre el cuartel general republicano. Como era de esperarse, ningún apoyo recibió el general Torres de los payaneses cuando tocó la alarma, pues casi todos huyeron despavoridos, y se comprobó, una vez más, el sentimiento de apego que todavía suscitaba en estos vecinos la figura del rey, que los hacía comparables en esos momentos con los pastusos. De igual modo, el cabildo terminó disuelto y sus miembros abandonaron la ciudad; algunos de ellos, sin pasaporte, mientras que funcionarios de rentas y correos se unieron también a la desbandada ${ }^{88}$.

No obstante, cuando don Basilio cumplía más de una semana de asedio, decidió abandonar la ciudad al convencerse de que no era fácil mantenerla ocupada militarmente y optó por retirarse a Pasto, pero no antes de dejar reactivadas las guerrillas patianas como punto infranqueable de defensa; fuerzas que cometieron atropellos por fuera del tratado de regularización de la guerra ${ }^{89}$.

Tras la retirada española, Torres logró recuperar el dominio sobre Popayán. Así entonces, después de culminado el tiempo de armisticio, de nuevo la situación se estancó, como estaba antes de la firma del tratado, pues ninguna de las dos fuerzas beligerantes lograba conquistas definitivas más allá de la frontera militar del valle del Patía, por lo que se prolongó un año más la lucha militar en estos territorios.

Aunque el general Bolívar había prometido liberar el sur en el mes de mayo, después de concluido el armisticio ${ }^{90}$, en fin de cuentas cambió de planes y enfocó su mira en la conquista de su natal Caracas. Después del triunfo alcanzado en la capital venezolana en el mes de julio y de la capitulación de la

\footnotetext{
${ }^{86}$ Cortázar (comp.), Cartas y mensajes, vol. 3, 169.

${ }^{87}$ Archivo Histórico Cipriano Rodríguez Santamaría, Fondo Manuel María Mosquera, caja 41, carpeta 4 , ff. $22 \mathrm{r}-23 \mathrm{r}$.

${ }^{88}$ Cortázar (comp.), Correspondencia dirigida, vol. 13, 159.

${ }^{89}$ López, Recuerdos históricos, 62.

${ }^{90}$ Cartas Santander-Bolivar, tomo 3, 87.
} 
plaza de Cartagena a principios de octubre, se despejó mucho más el camino para que el máximo oficial acopiara un mayor pie de fuerza para emprender, al año siguiente y bajo su mando, la gran operación militar para penetrar el territorio del Patía y el Juanambú hasta invadir Pasto, cuya rendición se dio finalmente el 6 de junio de $1822^{91}$, en medio de un ambiente favorable antecedido por el triunfo de la batalla de Bomboná y la liberación de Quito.

\section{A manera de colofón}

El objetivo último del armisticio, que fue crear el ambiente propicio para adelantar las negociaciones de paz que llevaran al fin de las guerras de Independencia, no se pudo cristalizar durante los seis meses que duró la tregua pactada en Trujillo. El presidente Simón Bolívar se mantuvo inamovible en su posición de exigir a España que reconociera a Colombia como un Estado libre y soberano.

Al momento de hacer un balance de la aplicación del armisticio en la región del sur, se pudo observar una atmósfera generalizada de incertidumbre, pues tanto el bando español como el bando republicano nunca dejaron de advertir a los oficiales en campaña que debían estar preparados ante la posibilidad de que se registrara una ruptura del acuerdo.

En cierta forma, los problemas suscitados en torno a la implementación de la tregua eran un reflejo del complejo teatro de la guerra vivido en este territorio ante el alto nivel de beligerancia y confrontación política y militar. Los republicanos debieron luchar por varios años contra un escenario adverso, que históricamente había planteado una resistencia a las ideas independentistas. Un espacio en el cual las lealtades resultaron mucho más vulnerables que en la costa caribe.

Durante el tiempo en que se mantuvo vigente el acuerdo, quedaron al descubierto vacilaciones y cambios de decisiones en torno a la culminación del tratado. Todo esto generó desconfianza y tensión entre las partes, a lo que se agregan las reiteradas posturas ambivalentes en el propósito de obtener mayores ventajas políticas y militares. También, se percibieron incongruencias entre los temas generales convenidos en Trujillo y la minucia de lo acordado por los delegados a nivel provincial. Frecuentes fueron las incertidumbres

91 "Correspondencia de la Secretaría General del general Bolívar" (Pasto, 1822), AGN, Sección República, Secretaría de Guerra y Marina, tomo 18, ff. 294r-329r; Sergio Elías Ortiz, Agustín Agualongo y su tiempo (Bogotá: Academia Colombiana de Historia, 1958), 445; Restrepo, Historia de la Revolución, tomo 3: 195. 
derivadas de los vacíos del acuerdo, como, por ejemplo, la delimitación de la línea divisoria en la costa pacífica. Estos factores, enmarcados en el afán de los contendientes de no menoscabar su poderío estratégico, se concertaron para provocar dilaciones, no solo en la notificación del acuerdo, sino también en el posterior proceso de fijación de límites.

El intenso cruce de cartas recriminatorias fue un reflejo de las repetidas infracciones a lo acordado en Trujillo y en Quito: el envío de tropas republicanas a Guayaquil, los ataques de las guerrillas del Patía y el cambio de bando de algunos de sus miembros, los combates entre pequeñas fuerzas regulares y los vacíos en materia de demarcación.

Si se establece una comparación con la experiencia vivida en las provincias de la costa caribe, se puede percibir en el territorio del sur una mayor influencia de la Iglesia, personificada en la figura del obispo Jiménez de Enciso y, por otro lado, una mayor participación y radicalización de los sectores populares, ya fuera a través de las guerrillas del Patía o de grupos civiles de resistencia. No obstante, hay que reconocer también que el armisticio significó un punto de inflexión en la férrea unidad monárquica que se vio resquebrajada por cuenta de una hábil campaña de persuasión por parte de los líderes republicanos y en la que, seguramente, influyeron también factores externos como la revolución liberal ocurrida en España a principios de 1820.

Aún con todos los tropiezos registrados, no hay duda de que el armisticio se constituyó en un corto respiro en la frenética y cruda lucha militar que se venía desarrollando en las provincias de Pasto y Popayán durante más de una década. En ese sentido, quizás el mayor legado del acuerdo fue el componente de regularización, pues las medidas humanitarias, como el canje de prisioneros, siguieron vigentes hasta la culminación de la guerra y significaron un alivio para las tropas en combate que estaban exhaustas y desgastadas a causa de la extrema confrontación, y que encontraron en la deserción y en el cambio de bando una nueva opción. Otros avances se dieron en materia de reactivación del flujo comercial y de garantías a los emigrados.

En resumidas cuentas, en asuntos de estrategia militar, se puede afirmar que las consecuencias del armisticio no fueron muy favorables para los intereses de las fuerzas patriotas. Sin embargo, si se hace un balance ponderado, hay que reconocer que se evitó una derrota ante la incuestionable superioridad militar de los españoles y, por otro lado, se contó con un lapso valioso mientras se reforzaban las debilitadas tropas y el general Bolívar afinaba los preparativos 
de la campaña que él mismo lideraría para expulsar definitivamente a los españoles de estas provincias.

Valga precisar que el sentimiento monárquico en esta región del sur no se exterminó del todo, pues en los tres años siguientes algunos reductos guerrilleros del Patía, así como fuerzas de resistencia en Pasto, mantuvieron férrea su oposición, aunque ya no con el mismo ímpetu de otrora pues fueron en parte neutralizados por las huestes republicanas.

Hay que tener presente, además, que el acuerdo firmado en Trujillo abrió el camino para la celebración de varios pactos en estas tierras del sur, como el armisticio firmado el 20 de noviembre de 1821 en Babahoyo entre Sucre y el coronel español Carlos Tolrá y el que se suscribió el 25 de mayo del año siguiente en Quito ${ }^{92}$, opciones de reconciliación que atenuaron los efectos de la guerra y allanaron el camino para la liberación definitiva de estas provincias.

\section{Referencias bibliográficas}

\section{Fuentes primarias}

\section{Fuentes manuscritas:}

Academia Colombiana de Historia. Bogotá-Colombia. Fondo Archivo del General Miguel de la Torre, tomo I.

Archivo Central del Cauca (ACC). Popayán-Colombia. Sala Independencia.

Archivo General de la Nación (AGN). Bogotá-Colombia. Fondos: Enrique Ortega Ricaurte, Historia, Negocios Administrativos, Secretaría de Guerra y Marina.

Archivo Histórico Cipriano Rodríguez Santamaría. Bogotá-Colombia, Fondo Manuel María Mosquera.

Biblioteca Nacional de Colombia (BNC). Bogotá-Colombia. Fondo Archivo Histórico Restrepo.

\section{Fuentes impresas / publicaciones periódicas}

Gazeta de la ciudad de Bogotá. Bogotá: Imprenta del Estado por Nicomedes Lora, 1821.

\section{Libros}

Actas del Congreso de Angostura 1819-1820. Bogotá: Biblioteca de la Presidencia de la República, 1988.

Archivo Santander. Bogotá: Águila Negra Editorial, 1916, tomo 5-6.

92 "Correspondencia de la Secretaría General del general Bolívar" (Pasto, 1822), AGN, Sección República, Secretaría de Guerra y Marina, tomo 18, ff. 314r-315v. 
Arroyo, Santiago. Apuntes históricos sobre la Revolución de la Independencia de Popayán. Bogotá: Ediciones Virtual, 2010.

Blanco, José Félix. Documentos para la historia de la vida pública del Libertador. Caracas: Ediciones de la Presidencia de la República, 1978, vol. 7.

Cartas Santander-Bolivar 1820-1822. Bogotá: Biblioteca de la Presidencia de la República, 1988, tomo 3.

Castrillón Arboleda, Diego. Manuel José Castrillón (Biografía y memorias). Bogotá, Biblioteca Banco Popular, 1971, tomo 1.

Cortázar, Roberto (comp.). Cartas y mensajes del general Francisco de Paula Santander. Bogotá: Academia Colombiana de Historia, 1956, vols. 2-3.

Cortázar, Roberto (comp.). Correspondencia dirigida al general Santander. Bogotá: Academia Colombiana de Historia, 1969, vols. 3, 4, 9, 12, 13.

Groot, José Manuel. Historia eclesiástica y civil de Nueva Granada. Bogotá: Editorial de Medardo Rivas, 1889, tomo 4.

Invitación hecha por el general Morillo al Congreso de los disidentes establecido en Guayana y a los jefes militares de los mismos para la terminación de aquella guerra y suspensión de hostilidades. Cádiz: Imprenta de Niel, hijo, Plaza de S. Francisco, 1820.

Lecuna, Vicente. Cartas del Libertador. Caracas: Fundación Vicente Lecuna, 1965 , tomo 3.

López, José Hilario. Memorias. Bogotá: Editorial ABC, 1942, tomo 1.

López, Manuel Antonio. Recuerdos históricos del coronel Manuel Antonio López, ayudante del Estado Mayor General Libertador, Colombia y Perú 1819-1826. Bogotá: Imprenta Nacional, 1955.

Martínez Delgado, Luis y Sergio Elías Ortiz (comps.). Epistolario y documentos oficiales del general José María Obando. Bogotá: Academia Colombiana de Historia, 1973, tomo 1.

Obando, José María. Apuntamientos para la historia. Bogotá: Editorial Bedout, 1972.

O'Leary, Simón B. Memorias del general O'Leary. Caracas: Imprenta de la Gaceta Oficial, 1983, tomos 17, 19, 29.

Ortiz, Sergio Elías (comp.). Colección de documentos para la historia de Colombia. (Época de la Independencia). Bogotá: Academia Colombiana de Historia, 1964, tomo 1.

Ortiz, Sergio Elías (comp.). Epistolario y documentos oficiales del general José María Obando. Bogotá: Academia Colombiana de Historia, 1973, tomo 1.

Restrepo, José Manuel (comp.). Documentos importantes para la historia de la Revolución de la República de Colombia en la América Meridional. Medellín: Universidad de Antioquia-Universidad Nacional, 2009, CD.

Restrepo, José Manuel. Historia de la Revolución de la República de Colombia. Bogotá: Editorial Besanzon, 1858, tomo 3.

Rodríguez Villa, Antonio. El teniente general don Pablo Morillo. Primer conde de Cartagena, marqués de la Fuerte (1778-1837). Madrid: Tipografía de Fortanet, 1910, tomo 4. 


\section{Fuentes secundarias}

Acosta de Samper, Soledad. Biografía del general Joaquín Acosta. Bogotá: Librería Colombiana, 1901.

Díaz de Zuluaga, Zamira. (1986). "La fuerza de trabajo en el Cauca Grande: 18101830”. En: Colmenares, Germán. Independencia: ensayos de historia social, editado por Germán Colmenares, 25-68. Bogotá: Instituto Colombiano de Cultura.

Earle, Rebecca A. España y la independencia de Colombia, 1810-1825. Bogotá: Universidad de Los Andes, 2014.

Guerrero Bucheli, Carol Estefanía y Gerardo León Guerrero Vinueza. El honor en Pasto durante la Independencia. "La defensa de la santa causa". Pasto: Universidad de Nariño, 2011.

Ibáñez, Roberto. "El Armisticio". En Historia de las Fuerzas Militares de Colombia, editado por Álvaro Valencia Tovar, tomo 1 “El ejército”,339-352. Bogotá: Editorial Planeta, 1993. 339-352.

Mercado, Jorge. Campaña de invasión del teniente general don Pablo Morillo 1815-1816. Bogotá: Editorial Iris, 1963.

Ortiz, Sergio Elías. Agustín Agualongo y su tiempo. Bogotá: Academia Colombiana de Historia, 1958.

Pérez O., Eduardo. La guerra irregular en la Independencia de la Nueva Granada y Venezuela 1810-1830. Tunja: UPTC, 1982.

Plazas Olarte, Guillermo. "Historia Militar". En Historia extensa de Colombia. Bogotá: Ediciones Lerner, 1970, vol. 18, tomo 3.

Thibaud, Clément. República en armas. Los ejércitos bolivarianos en la guerra de Independencia en Colombia y Venezuela. Bogotá: Planeta-Ifea, 2003.

Zuluaga, Francisco. Guerrilla y sociedad en el Patía. Una relación entre el clientelismo político y la insurgencia social. Santiago de Cali: Universidad del Valle, 1993. 